\title{
Research on the Practice Courses Based on the Simulation Laboratory in ESP Learning
}

\author{
C.S. JIANG \\ Beijing Wuzi University, Beijing
}

\begin{abstract}
ESP has become a main strand of college English learning in some non-English speaking countries, such as China. But the effect of ESP learning in China is not so optimistic or satisfying, which is only regarded as another name for General English. The ESP learners can hardly benefit from the course they have learnt on campus. They have to take some specific language training before they can use the language frequently in their future work. The situation is mainly due to the lack of practice courses in the real circumstances when they are having the courses at school. According to Communicative Needs Theory, the language users can be easily disturbed when the communicative environment is changed, their flexibility to use languages, tolerance for error of languages, discourse styles, repetition and hesitation are also surly different. Therefore the practice courses in the stimulation laboratory are required, which can set up the real situation without the limitation of places or time, to meet the needs of the different target scenarios. The paper concludes that the practice courses in the simulation laboratory are necessary and highlighted in ESP learning which will be the bridge for the newly-graduates and the real working environment.
\end{abstract}

KEYWORD: Communicative Needs; the simulation laboratory; ESP learning

\section{INTRODUCTION}

\subsection{The specific features of ESP learning}

The concept of ESP, English for Special Purpose, is first come up by Halliday in 1964 and developed by Strevens, Hutchinson and Waters in the later time. According to Strevens, ESP courses are those in which the aims and content are determined, principally or wholly not by criteria of general education but by functional and practical English requirement of learners[1]. While Hutchinson and Waters hold the different idea that ESP shouldn't be regarded as a product but an approach, an approach to language teaching which aims to meet the needs of particular learners. No matter which definition, one important point in common is that ESP learning is definitely different from EGP, which is English for General Purpose, since ESP is related to some specific field and needs to meet particular purposes. ESP learning definitely has its own specific features. Firstly, ESP learners are usually goal oriented. Most part of reasons why the learners study ESP is for the practical use for their future jobs.

Secondly, ESP learning should be authenticating, not only for the reading material but also for the communicative tasks during the learning process. Staurt shows the authenticity both in reading materials and communicative strategy in his book The Non-specialist use of Foreign Languages in Industry and Commerce. All of the materials in his book are from the real business cases.

\subsection{The problems of ESP learning in China}

The concept of ESP was introduced into China in 1970s and has a rising trend since the late of 1980s. The courses are commonly taken as a pre-career training course for the junior and senior students after they finish two years' General English learning at college. Although ESP has been taken in the higher education procedure for nearly half a century, the learning results are not optimistic or satisfying. The students are lack of inner-motivation. They don't think the ESP is different from EGP (English for General Purposes) since they have no special method to finish their ESP learning and tend to focus their attention on the text reading or terms reciting, or even reciting the whole passage to complete the learning without or with less practice courses, which depends on the possibility of place and time arranged by the teaching units. And we all know that there are a lot of difficulties for the university to arrange all students to practice in the real working situation.

So the most common practice trainings for them 
in the learning process at school is repeating the dialogues of the text or doing role-play on class. The results of learning for them are not satisfied. They achieve less after their hard-working learning, comparing with the time and energy they consume. They can hardly use English properly when they are in the real working situations. A lot of studies show that a lack of the practice courses or practical training will hardly benefit for the learners. Once they stop learning, their ability to use the language will regress a lot. They tend to forget what they have learnt. Besides, only the dialogue reciting and terms memorizing in the learning procedure can easily make the learners bored, so the learners can hardly keep a constant interest.

\section{THE NECESSITY OF THE PRACTICE COURSES IN IN ESP LEARNING}

\subsection{An urgent need for practice courses in ESP learning}

As Swales, who is professor teaching ESP in England and America for many years said, although majority of "ESP courses are designed to help their customers to survive and succeed in an academic environment,..... at a training level, practice courses will no doubt benefit students in both their academic fields and their future work."[2]. Back in the 1996, Liu Ruiqing also said ESP would be the main trend in college English in 21 Century[3]. It is necessary and urgent for the learners to find a better way to get a higher achievement. Therefore the fully inte-grated learning design with real practice courses has become an urgent need for ESP learning.

\subsection{Communicative Needs in ESP Learning}

According to Munby's opinion in his communicative Syllabus Design in 1978, the eight categories of Communicative Needs Processor(CNP) are concerned with the end product idea of learning. Among the eight categories, four of them directly imply the importance of practice courses, namely the setting, the interaction, communicative event and the learners' manner and behavior. The setting include the time and place in which the target language is used. It includes physical and psychological setting, which has direct connection with the next categoryinteraction since it contains the language user's selfidentification and evaluation [4]. As for the other two categories of CNP, the effect of the language users are all related to the target activities. The language user will behave differently according to the different situation. That means the language learners are easily affected by the change of any factors in the categories.

Considering this situation, many researchers suggest that the practice courses in the ESP learning should be emphasized[5]. The classroom learning is defiantly different from the real environment since the setting and the people they are talking to, namely the target communication are all happened in a fake environment. Most of the learners still confuse when they are in the real situation. Because of that, the practice courses in real situation are high lightened. The language learners can practice and grasp the language skills and some specific knowledge in the real environment since it can provide the real situation.

\section{THE FEASIBILITY OF SIMULATION LAB IN THE PRACTICE COURSES}

\subsection{The simulation lab in the network environment}

Simulation Laboratory based on network and computers is a kind of lab which can provide a virtual simulation environment. It is currently used in the fields of science fields, such as physics, chemistry, biology, medicine, etc. which is seldom used as language laboratory. In fact the similar forms of simulation games have been in use in business school since 1957 in western countries[6]. Faria reported that $95.1 \%$ of AACSB member schools used at least one business simulation game in their program during 1985-1986 academic year. And the business simulation game usage in academia and in industry has continued to grow over the past 10 years with expectations for further growth[7]. Just as what the survey showed that the simulation games are in use only in a very narrow scale of fields, most probably in business. While same as the simulation games used in the business field, the simulation labs equipped with web-based and software-based computers have similar functions. It is actually like an online computer games which show the simulation environment. Through virtual network platform, the ESP learners can learn not only language, but also the cultural experiences and so on.

\subsection{The simulation labs based on network technology are easily constructed.}

The simulation labs with experimental projects basically depend on network. The construction of simulation labs for ESP is easy to be set up, which can provides a new way for practical ability and innovation ability training for ESP. Firstly, with the development and popularization of network technology, it is very common to have network in the universities in China. For ESP learners, most of them are college students. They know how to use computers and internet to carry out the technical operations. Secondly, language labs are the common facilities in the universities which can be equipped as the simulation labs with specific software. The 
software can be easily installed in computers. Besides, more and more software, for example $21^{\text {st }}$ City, professional simulation software for business English, has been designed to meet the specific fields.

\subsection{The positive results of the simulation labs}

The simulation laboratory can definitely provide positive result.

\subsubsection{It can meet the learners' individual needs}

Since the software is task-oriented, the learners can choose the different level according to their own level, which can meet the different needs in the maxi degree. Some learners can also set their own level and speed to finish the tasks. It will surly satisfy learners with different levels.

\subsubsection{Tasks-oriented courses are like computer Games.}

The software has some tasks-oriented design which can constantly arouse the learners' attention to trigger their learning desire. In this process, the learners notice their problems in the use of language, and then issue a conscious analysis, and then revise their output, and finally increase their language fluency and accuracy. A study explores the importance of the self-controlled games can examine the role of individual differences and satisfaction with the game as a learning tool. Results produced through the use of the game indicate that students tend to use what they have learnt in the games. Individual needs for achievement are associated with satisfaction with the game as a learning tool[8].

\subsubsection{High efficiency and low cost.}

As what mentioned above, simulation labs are easy to set up, with efficiency results and low cost. In traditional method, practice course need to contact the different working units to negotiate the time and place to practice, and some of arrangement has to be canceled because of some reasons. Sometimes the working units don't welcome students to practice there since some tasks are dangerous or high-risk. In that case, the simulation labs can deal with the problems since all simulation environment are virtual.

Similar to the simulation games, ESP simulation software can be divided in to different fields. In each field, there are different levels. For each level there are different tasks with relevant topics and scene settings, such as job candidates, business negotiations, courting and so on. What the learners should focus on are not only their language skills and professional knowledge, but also the relevant cultural awareness. Throughout the operational aspects of the practice, they can achieve a personalized progress.

Of course, the method of practice courses in ESP shouldn't be limited. In addition to the simulation laboratory, the learners are also encouraged to practice role play in class or doing practice in the real situation. Combining the different ways is to get the better output.

A recent survey shows that ESP learners should maintain and enhance their own' interest and motivation in their ESP learning. Teachers should try to create a pleasant learning atmosphere, use different simulation scenarios to stimulate students' internal motivation. ESP learning procedure should be added as many practice course as possible.

\section{CONCLUSIONS}

The practice courses in simulation labs need to be strengthened in ESP learning. For language users, the increasingly developed information technology provides the possibility of practicing in simulation labs with low cost. The ESP learners can choose the different field and level to practice the communication activities without or with less limitation of time and place. Traditional means of learning method can't meet the need in the modern society. Educational technology and methods directly affect the teaching results. At this point, the use of simulation laboratory application, from multi-angle, multi-level, can not only bring significant results in ESP learning, but also very practical. Through arranging different scenarios modules and tasks, the learners can not only learn specific knowledge, but also get the cultural awareness, which will definitely act as a bridge between newly graduates and their future jobs. Furthermore, the assessment for the practice courses should not be limited. The diverse assessments for ESP practice courses should be highlighted. Making full use of simulation labs and meanwhile broaden the concept of practice courses will defiantly produce the better results for ESP learning.

\section{REFERENCES}

[1] Strevens P. 1977. New Orientation in the Teaching of English. Oxford University Press.

[2] Swales J. 1985 Writing Specific English Oxford.

[3] Liu R.Q 1996, English Teaching in $21^{\text {st }}$ Century. Foreign Language Teaching and Research Press -02 .

[4] Munby J. 1978 Communication Syllabus Design. Cambridge University Press.

[5] Dudley T. 1998. Developments in English for Specific Purposes. Cambridge Language Teaching Library.

[6] Hewing M. 2002 A History of ESP through 'English for Specific Purposes'- 01.

[7] Faria, A.J. 1998: Journal of Management Development, Business simulation games: Current usage levels: the update of simulation and gaming Vol. 13, No. 1, pp. 47-59. 